\title{
Extracellular Multi-Unit Recording from the Olfactory Nerve of Teleosts
}

\author{
Peter Hubbard ${ }^{1}$, Zélia Velez ${ }^{1,2}$ \\ ${ }^{1}$ Centro de Ciências do Mar ${ }^{2}$ Universidade do Algarve
}

\section{Corresponding Author}

Peter Hubbard

phubbard@ualg.pt

\section{Citation}

Hubbard, P., Velez, Z. Extracellular Multi-Unit Recording from the Olfactory Nerve of Teleosts. J. Vis. Exp. (164), e60962, doi:10.3791/60962 (2020).

\section{Date Published}

October 6, 2020

DOI

$10.3791 / 60962$

URL

jove.com/video/60962

\section{Abstract}

Recent studies have shown that ocean acidification affects olfactory-driven behavior in fish. This may be due in part to a reduction in olfactory sensitivity in high $\mathrm{PCO}_{2} / \mathrm{low} \mathrm{pH}$ water. To assess the effects of ocean acidification, or olfactory sensitivity in marine fish in general, we propose that extracellular multi-unit recording from the olfactory nerve is the method of choice. Although invasive, it is sensitive, robust, reproducible and independent of external salinity (unlike the electro-olfactogram [EOG], for example). Furthermore, it records a primary sensory input into the CNS, prior to any central processing. We show that this method can show a reduction in olfactory sensitivity that is both temporary and odorant-dependent, using a range of amino acids to construct concentration-response curves and calculate the thresholds of detection.

\section{Introduction}

Fish rely heavily on olfaction for many aspects of their lives including finding food, avoiding predators, assessing potential mates and migration, among others ${ }^{1,2,3}$. Therefore, assessing olfactory sensitivity in fish (What do they smell? How sensitive are they to these compounds?) is vital to fully understand these processes. Furthermore, anthropogenic effects on the environment, such as ocean acidification and pollution, may have profound effects on the olfactory system, even at sublethal levels, because it is necessarily in intimate contact with the surrounding water ${ }^{4}$. In vivo electrophysiology is the experimental approach of choice to assess olfactory sensitivity in fish. Three main techniques are available: the electro-olfactogram (EOG), the electroencephalogram (EEG) recorded from the olfactory bulb, and multi-unit recording from the olfactory nerve ${ }^{5}$.

The EOG is the most widely used of these three ${ }^{6}$. It is a direct current (DC) field potential recorded above the olfactory epithelium and is believed to be the summed generator potentials of those olfactory receptor neurons (ORNs) responding to a given odorant. However, as it is recorded in the water, rather than inside the fish, the amplitude of response is not only dependent on the signal 
generated by the fish, but also on the conductivity of the surrounding water; the higher the conductivity (or the lower the resistance), the lower will be the amplitude. This may mean that the EOG is a less sensitive method in seawater than freshwater ${ }^{7}$.

The EEG recorded from the olfactory bulb is also widely used in investigation of olfaction in fish. However, the olfactory bulb is the first-order processing center for olfactory sensory input $^{8}$; it is highly organized into glomeruli, and consequently the response recorded depends heavily on the position of the recording electrodes. For example, the input from ORNs detecting amino acids is processed by glomeruli in the lateral region of the olfactory bulbs, whereas that from conspecific-derived chemicals is directed to the medial region $^{9,10,11,12}$. Pheromonal input may be directed to highly localized glomeruli within the olfactory bulb. Depending also on the anatomy of the species in question, the ideal recording position for a given odorant may not be easily accessible.

Multi-unit recording from the olfactory nerve circumvents the main problems with the EOG and EEG outlined above. As it records actions potentials passing down the axons of the ORNs from the epithelium to the bulb, it is a primary sensory signal. And as it is recorded inside the fish, the amplitude of response is independent of external salinity. Nevertheless, of course it has some disadvantages. Firstly, depending on the anatomy of the species, more extensive surgery is required to expose the olfactory nerve than for the EOG. Secondly, because the signal is smaller than the EOG, it requires slightly more sophisticated, and therefore expensive, equipment. A general description of other experimental approaches is given by John Caprio ${ }^{5}$. The aim of this article is to outline how to record extracellular multi-unit responses from the olfactory nerve of the seabream (Sparus aurata) in vivo to amino acid odorants as an example of this technique, and how to identify, and overcome, some of the more common problems encountered in such an experiment.

\section{Protocol}

Animal maintenance and experimentation was carried out in certified experimental facilities and followed Portuguese national legislation (DL 113/2013) under a 'group-1' license by the Veterinary General Directorate, Ministry of Agriculture, Rural Development and Fisheries of Portugal. As this protocol involves animal handling, it has to be approved by the local and/or national body that regulates welfare of animals used in scientific experiments, in addition researchers need to have the appropriate training and licenses to carry out such procedures.

\section{Stimulus preparation}

NOTE: Most fish have highly sensitive olfactory system, thus great care must be taken when preparing the olfactory stimuli to be used in the experiment. The glassware used to make up the stimuli should be washed in $5 \%$ bleach (sodium hypochlorite), rinsed thoroughly with tap water and dried. Immediately prior to use rinse the glassware thoroughly with seawater (the same water used to make the stimulus dilutions). Take care that none of this water comes into contact with bare skin.

1. Make $100 \mathrm{~mL}$ of $10^{-2} \mathrm{M} \mathrm{L-glutamine,} \mathrm{L-leucine} \mathrm{and} \mathrm{L-}$ serine; store $1 \mathrm{~mL}$ aliquots of each at $-20{ }^{\circ} \mathrm{C}$ until use.

2. On the day of the experiment, prepare from these aliquots, $10^{-3} \mathrm{M}$ to $10^{-7} \mathrm{M}$ solutions (in steps of $\mathrm{x} 10$ dilution) using both control and high $\mathrm{CO}_{2}$ seawater. 
NOTE: L-serine $\left(10^{-3} \mathrm{M}\right)$ will be used as a positive control, or standard. Water used to make up the dilutions of the stimuli, and treated in exactly the same way as the stimuli but without addition of any odorant, will be used as the negative control or blank.

\section{Preparation of control and high $C Q$ water}

1. Prepare control water by collecting $1 \mathrm{~L}$ of charcoalfiltered seawater.

1. Using a pH probe, check the $\mathrm{pH}$; it should be around 8.2. If not, bubble with atmospheric air until this $\mathrm{pH}$ is reached.

2. Using an alkalinity titrator measure the alkalinity of the water.

3. Measure the water temperature and salinity.

2. Prepare high $\mathrm{CO}_{2}$ water by filtering $1 \mathrm{~L}$ of sea water, then bubble $\mathrm{CO}_{2}$ until the desired $\mathrm{pH}$ is reached.

1. Using a pH probe, check the $\mathrm{pH}$; it should be around 7.7.

2. Using an alkalinity titrator, measure the alkalinity of the water.

3. Measure the water temperature and salinity.

3. Determine $\mathrm{CO}_{2}$ pressure in both control and high $\mathrm{CO}_{2}$ water using a software designed to calculate $\mathrm{CO}_{2}$ parameters in water (e.g., CO2Calc software ${ }^{13}$ ).

1. In the input window add the values of water $\mathrm{pH}$, temperature, salinity and total alkalinity (Figure 1).

2. Select the constants, units and scales (see the recommended values in Figure 2).
3. Press the button process to determine $\mathrm{CO}_{2}$ pressure.

NOTE: Figure 3 shows an example of a result sheet.

\section{Preparation of the fish}

NOTE: A seabream of $200-400 \mathrm{~g}$ is used in this protocol.

1. Anesthetize the fish byimmersion in aerated natural seawater containing MS222 (ethyl-3-aminobenzoate methanesulfonate salt). When response to a tail pinch has stopped, inject into the flank muscle the neuromuscular blocker gallamine triethiodide (10 $\mathrm{mg} \cdot \mathrm{kg}^{-1}$ in physiological saline).

NOTE: The concentration of anesthetic used varies among species; for a seabream of $200-400 \mathrm{~g}$, use 200 $\mathrm{mg} \cdot \mathrm{L}^{-1}$ buffered with $400 \mathrm{mg} \cdot \mathrm{L}^{-1} \mathrm{NaHCO}_{3}$

2. Place the anesthetized fish on a cushioned support. The exact shape and size depend on the model species; for seabream (200-400 g), use a padded V-shaped support, made in house.

3. Place a silicon tube (diameter $=10 \mathrm{~mm}$ ) in the mouth, connect the tube to a submersible pump in a reservoir of anesthetic-containing, aerated seawater, and pump water over the gills at $\sim 100 \mathrm{~mL} \cdot \mathrm{min}^{-1} \cdot \mathrm{kg}^{-1}$.

NOTE: The size of the silicon tube used will depend on the size of the fish.

4. Insert the earthing pin into the flank muscle and connect it to the head-stage of the amplifier).

5. Cover the fish with damp cloth (or paper towel) with only the head exposed, ensuring that the covering does not impede the exit of water from the gills. 
NOTE: The eyes can be covered with pieces of damp paper/cloth or black plastic.

6. Position the tube of the stimulus-delivery system, i.e., the glass tube connected to a supply of background seawater, into the nostril.

NOTE: Micro-hematocrit tubes can be used (length $=75$ $\mathrm{mm}, \mathrm{ID}=1.15 \mathrm{~mm}, \mathrm{OD}=1.55 \mathrm{~mm}$ ); these can be pulled to a finer point on an electrode puller for use with smaller fish. It is important to ensure that the olfactory epithelium is kept wet during the surgery (described below).

7. Expose the olfactory nerves by removing the skin and bone of the skull between the eyes (the olfactory nerves usually run together between the eyes) with the aid of a dental (ideally) or hobby (e.g., Dremel) drill or jeweler's polisher (with dental drill-bits) under a dissecting microscope (inside a Faraday cage).

1. In the seabream, remove the part of the skull immediately above the eyes, with a circular saw, from just anterior to the eyes to just posterior to them. Then, using a drill bit, remove the bone between the eyes; the olfactory nerves lie between the eyes.

8. Once sufficient bone has been cleared, remove the fat and connective tissue overlying the nerves using fine forceps; take care to not damage the nerves or puncture any blood vessels.

NOTE: Experience will help to refine the dissection; the smaller the dissection, the more stable the preparation will be. However, sufficient tissue must be cleared; for the unexperienced, when the olfactory bulbs are just visible, clear slightly more anteriorly to expose the part of the nerves as they join the bulbs to allow the correct positioning of the electrodes.
9. Clean the electrodes prior to use by connecting them to negative pole of a $3 \mathrm{~V}$ DC source (e.g., two AA batteries in series) and placing the tip in physiological saline (or seawater diluted 1:3 in freshwater) for $20-30 \mathrm{~s}$; a steady stream of small bubbles should be seen coming from the tip.

10. Once the olfactory nerves are exposed, insert the recording electrodes (held on micro-manipulators) in a position that gives a maximal response to the standard (e.g., $10^{-3} \mathrm{M}$ L-serine), and a minimal response to the blank. Use parylene-coated tungsten electrodes (Table of Materials) connected to the head-stage of an alternating current $(A C)$ preamplifier.

NOTE: In the seabream, the strongest responses to amino acids are usually seen with the electrodes placed in the lateral side of the nerve, close to where it joins the olfactory bulb. This may hold true for other species, as the glomerular organization of the bulb is broadly similar among species. However, experience is always the best teacher.

\section{Electrophysiological recording}

NOTE: As with most electrophysiology, multi-unit recording needs to take place within a Faraday cage. However, extracellular recording does not usually require an antivibration table; most movement will come from the fish. Nevertheless, a strong, stable table is required with a metal surface to secure the magnetic bases of the micromanipulator stands.

1. Set up a stimulus delivery system to allow the rapid switching from clean background water to stimuluscontaining water, e.g., by using a solenoid-operated three-way valve. Connect the common outlet to the tube 
carrying water to the olfactory rosette, and place one line in a seawater reservoir and the other in the test solution. NOTE: When the valve is switched (by passing DC current), the water flow switches from background water to that containing the odorant. The stimulus should be given for long enough to see a clear peak in the integrated response, followed by a period of accommodation; the time used in the current protocol is $4 \mathrm{~s}$, but longer time may be necessary depending on the species.

2. Connect the valve driver to the trigger of an analoguedigital converter (e.g., Digidata); when the valve is switched from background to stimulus-containing line, this will start the recording of the data. Configure the software to start recording at the trigger event and continue for a predetermined period (e.g., $10 \mathrm{~s}$ ).

NOTE: Ten seconds should be enough, but this can be shortened or lengthened, depending on the experimental question.

3. Check the stability of the preparation by testing (recording and measuring the amplitude of the integrated response) repeatedly with the standard, $10^{-3} \mathrm{M} \mathrm{L-serine}$ in this case, and allowing $1 \mathrm{~min}$ to elapse between successive stimuli.

NOTE: Depending to some extent on species and odorant, the responses should have an amplitude within $10 \%$ of each other (as a rule of thumb), and should have a rapid onset, rise to maximum activity, and return to baseline after the stimulus is absent (Figure 4).

4. Record the olfactory nerve responses to amino acids in control sea water (from the lowest to the highest concentration) and allow $1 \mathrm{~min}$ to elapse between successive stimuli.
NOTE: It is possible that, for some species and/or some odorants, more time is necessary. But for amino acids and seabream, $1 \mathrm{~min}$ is sufficient.

5. Record the response to $10^{-3} \mathrm{M}$ serine and a control water blank solution.

6. Change the background water from control seawater to high $\mathrm{CO}_{2}$ seawater, by placing the background line into the bottle with high $\mathrm{CO}_{2}$ seawater.

NOTE: It is advisable to insert another hematocrit tube (or equivalent) into the end of the stimulus and background lines to avoid touching the water and ensure the end of the tube remains in the water.

7. Prior to testing the response of the olfactory nerve to amino acids in high $\mathrm{CO}_{2}$ seawater, condition the olfactory epithelium with high $\mathrm{CO}_{2}$ water by following the high $\mathrm{CO}_{2}$ water over the olfactory epithelium for a few minutes.

NOTE: Experience has shown that, for seabream, $5 \mathrm{~min}$ is sufficient.

8. Record the olfactory nerve responses to amino acids in high $\mathrm{CO}_{2}$ seawater (from the lowest to the highest concentration).

9. Record the response to a high $\mathrm{CO}_{2}$ water blank solution.

10. Record the response to $10^{-3} \mathrm{M}$ serine and a control water blank solution.

NOTE: The raw signal (nerve activity) should be filtered (low pass around 2,000-5,000 Hz, high pass $50-300 \mathrm{~Hz}$ ) and passed to an analogue-digital converter (Table of Materials). For easier quantification of nerve activity, the raw signal can also be integrated using a leaky integrator (Table of Materials) and passed to the analogue-digital converter, and from there, both raw and integrated 
signals to a computer running the appropriate software (e.g., Axoscope).

\section{Data analysis}

1. Subtract the amplitude of the integrated response to the blank (in $\mathrm{mV}$ ) from the amplitude of the integrated responses to all stimuli.

2. Normalize responses to stimuli by dividing the amplitude of the previous response to the standard $\left(10^{-3} \mathrm{M}\right.$ serine); this reduces inter- and intra-fish variability.

3. Calculate the thresholds of detection by linear regression of the concentration-response curves (on a semilogarithmic plot), according to the formula $\log (N+1.5)$ $=\operatorname{alog} C+B$, where $C$ is the molar concentration, $N$ is the normalized response amplitude, and $a$ and $b$ are constants $^{7,14}$.

NOTE: The threshold of detection is then the value for $x$ where $y=0.1761$ (i.e., $\log 1.5 ; N=0$ ); the concentration above which a response will be seen (i.e., the fish can smell it). Some odorants evoke sigmoidal concentrationresponse curves when plotted semi-logarithmically (e.g., calcium $^{15,16}$; in this case, the normalized data can be fitted to a three-parameter Hill plot which will give the maximum response amplitude and the $\mathrm{EC}_{50}$ (i.e., [odorant] that gives half-maximum response; also a measure of sensitivity).

4. Compare the thresholds of detection and/or the maximum response amplitude and the $\mathrm{EC}_{50}$ of stimuli tested in control water and those tested in high $\mathrm{CO}_{2}$ water.

\section{Representative Results}

A typical response to the positive control $\left(10^{-3} \mathrm{M} \mathrm{L-serine;}\right.$ Figure 4A) and negative control (blank; Figure 4B) recorded from the olfactory nerve of a seabream is shown in Figure 4. In the presence of the stimulus (black horizontal bar; in the olfactory cavity, in contact with the olfactory epithelium), note the rapid increase in activity (reflected in the upward deflection of the integrated signal) to a peak within about one second of stimulus onset, followed by a period of accommodation (while the stimulus is still present), and a return to baseline activity once the stimulus has ended. The absolute amplitude of the response is highly dependent on electrode position; if a low amplitude response is recorded, try changing the electrode positions. A slower rise to peak activity may be due to the tube carrying the stimulus-containing water to the olfactory epithelium being placed too far away from the epithelium; try moving the nose-tube closer to (but not touching) the epithelium. Note that, in contrast, the blank evokes little or no response. A significant positive response (i.e., increase in activity) to the blank may indicate contamination of the water used to make the dilutions of the stimuli; making fresh dilutions with clean water (and glassware) should resolve this. If not, a more thorough cleaning of the water system (including activated charcoal filters) may be necessary. A negative response (i.e., decrease in activity) may indicate a slight change in flow rate when the valve is switched due to, for example, a blockage in the valve. 
A typical concentration-response curve (plotted semilogarithmically), in this case to L-leucine $\left(10^{-7} \mathrm{M}\right.$ to $\left.10^{-3} \mathrm{M}\right)$, is shown in Figure 5A. Note that increasing concentrations of the odorant evoke increasingly large increases in activity, and therefore, in the amplitude of the integrated responses. A plot of the normalized data, and their corresponding linear regression, is shown in Figure 5B. The estimated threshold of detection can be calculated from the value of $x$ when $y$ $=0.1761$ (i.e., $\log 1.5$; where $N=0$ ). In this case, this value is -7.48; that is, the calculated threshold for L-leucine in this fish is $10^{-7.48} \mathrm{M}$. The exponent $\alpha$ can similarly be estimated from linear regression of the normalized data on a log-log plot; $\log N=\alpha \log [$ odorant] + constant. The factor $Y$ then gives the increase in odorant concentration required to increase the response amplitude by one log unit; that is, it is an estimate of the steepness of the concentration-response curve ${ }^{17}$. In this example, $\alpha=0.277$ and $y=3.61$; therefore, to increase the response amplitude ten-fold (i.e., one $\log$ unit; $\log 10=1$ ), the stimulus concentration needs to be increased by $10^{3.61}$-fold (4,074-fold).

A typical sigmoidal concentration-response curve (Figure 6A) when plotted semi-logarithmically, in this case to L-glutamine, is shown in Figure 6B. A similar concentration-dependent increase in response amplitude is seen; however, at the higher concentrations, this increase becomes less so that the response amplitude reaches a maximum $\left(N_{\max }\right)$. This allows the data to be fitted to a three parameter Hill equation:

$\frac{N}{N \max }=\frac{[\text { odorant }] n}{(\text { EC50n+[odorant }] n)}$

This way, the $\mathrm{EC}_{50}$ (the odorant concentration at which a $50 \%$ maximal response is evoked) and the Hill co-efficient (a measure of the steepness of the slope of the linear part of the sigmoidal curve) can be calculated. 


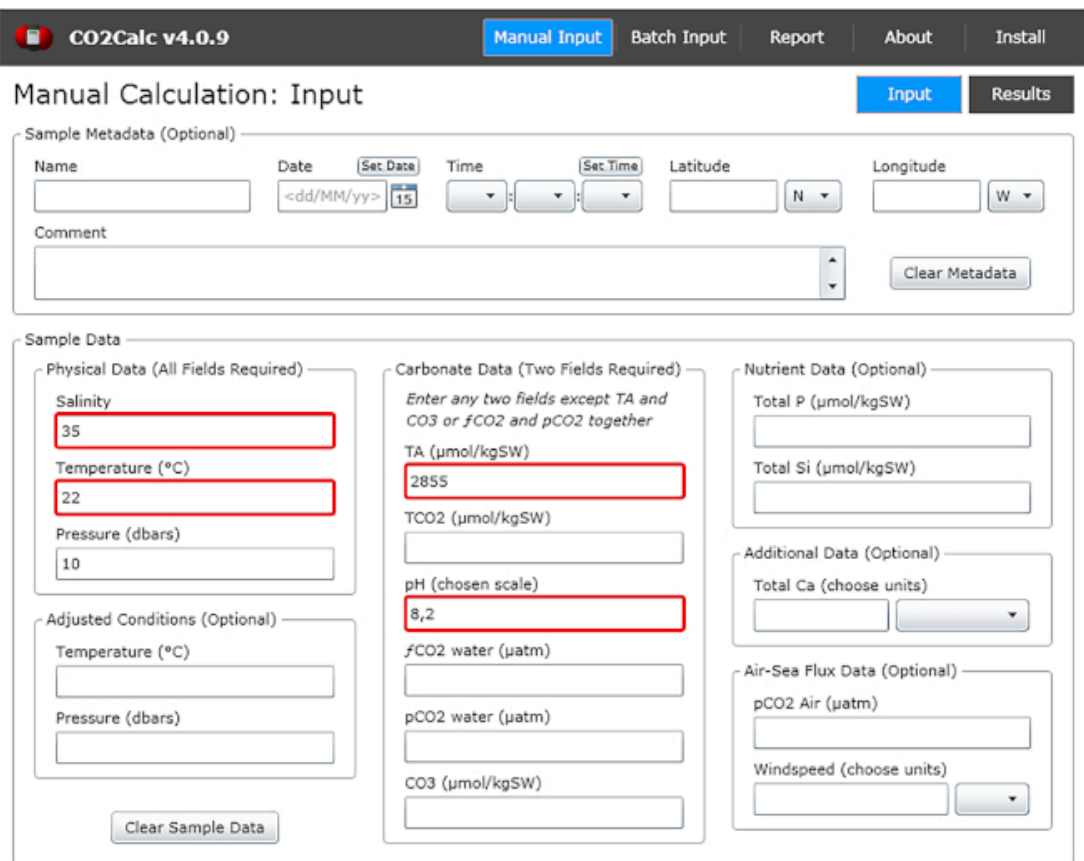

Figure 1: Software screenshot showing the input window from the program CO2Calc. Highlighted (red boxes) are the fields required for carbonate parameter calculation. Please click here to view a larger version of this figure.

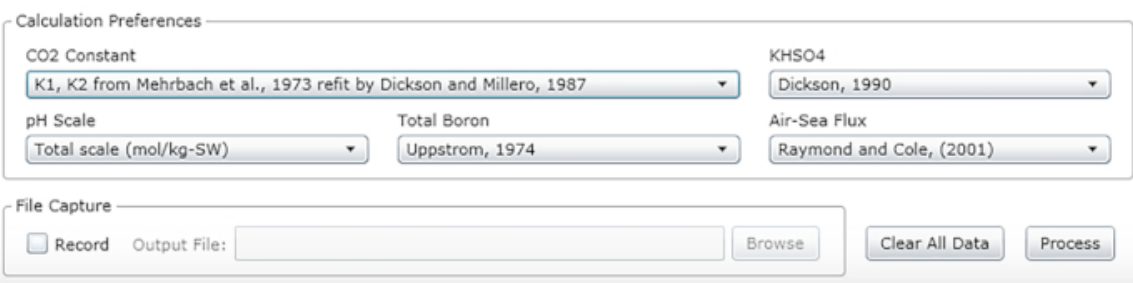

Figure 2: Software screenshot showing the input window for the appropriate constants, units and scales. Values shown are recommended for conditions under which the described experiments were carried out; they may change. Please click here to view a larger version of this figure. 


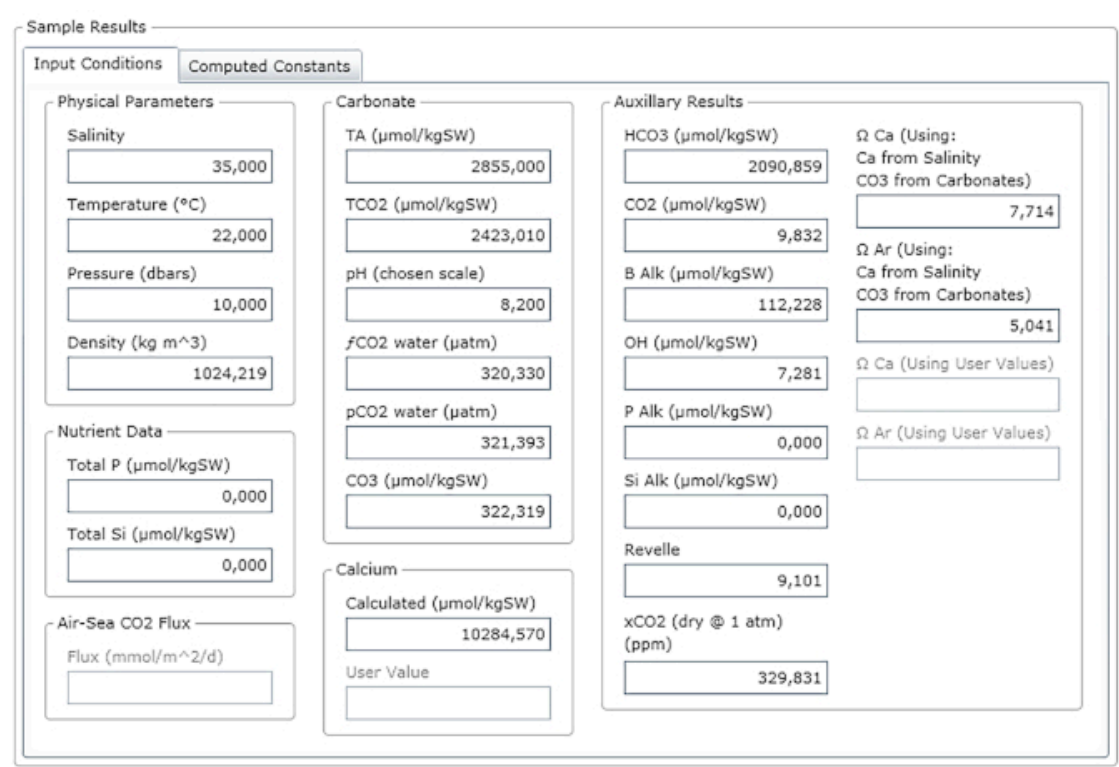

Calculation Preferences

CO2 Constant: K1, K2 from Mehrbach et al., 1973 refit by Dickson and Millero, 1987

pH Scale: Total scale (mol/kg-SW) KHSO4:

Total Boron: Uppstrom, $1974 \quad$ Air-Sea Flux:

Figure 3: Software screenshot showing the results window. Please click here to view a larger version of this figure. 


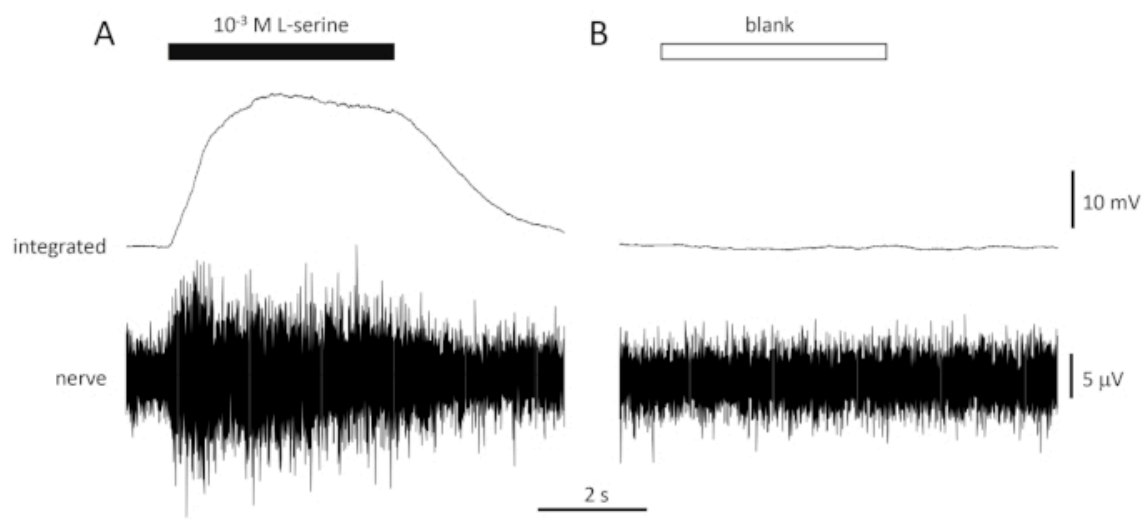

Figure 4: Typical multi-unit responses recorded extracellularly from the olfactory nerve of seabream in vivo in response to $10^{-3} \mathrm{M}$ L-serine (A) and blank (B). Upper traces show the integrated responses and lower traces show the raw (nerve) signal. Stimuli were applied to the olfactory epithelium (horizontal bars). Note the rapid increase in activity during the $1 \mathrm{~s}$ of exposure, a peak in activity, followed by a period of accommodation (while the odorant was still delivered to the epithelium) and a return to baseline levels once the odorant delivery has ceased. Little or no increase in activity is seen following stimulation with water treated the same way as odorant dilutions, with the exception of adding any odorant (blank). Please click here to view a larger version of this figure. 
A

$10^{-7} \mathrm{M}$ L-leucine $\quad{ }^{10^{-6} \mathrm{M} \text { L-leucine }} \quad{ }^{10^{-5} \mathrm{M} \text { L-leucine }} \quad{ }^{10^{-4} \mathrm{M} \text { L-leucine }} \quad{ }^{10^{-3} \mathrm{M} \text { L-leucin }}$

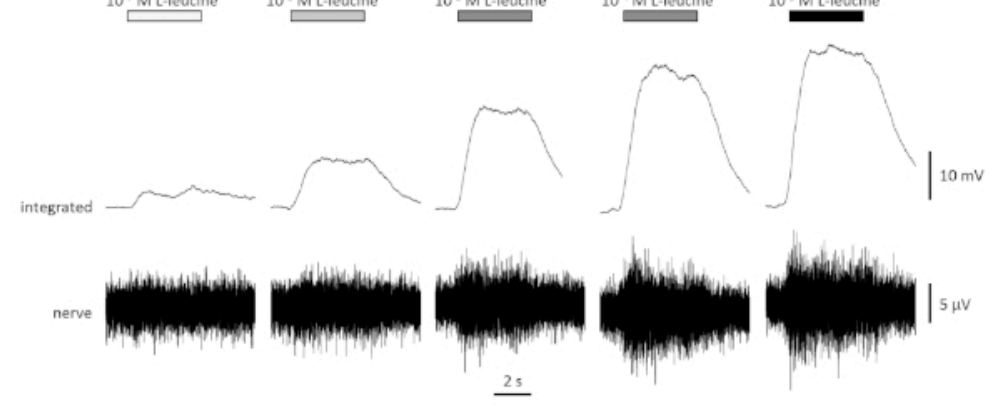

B

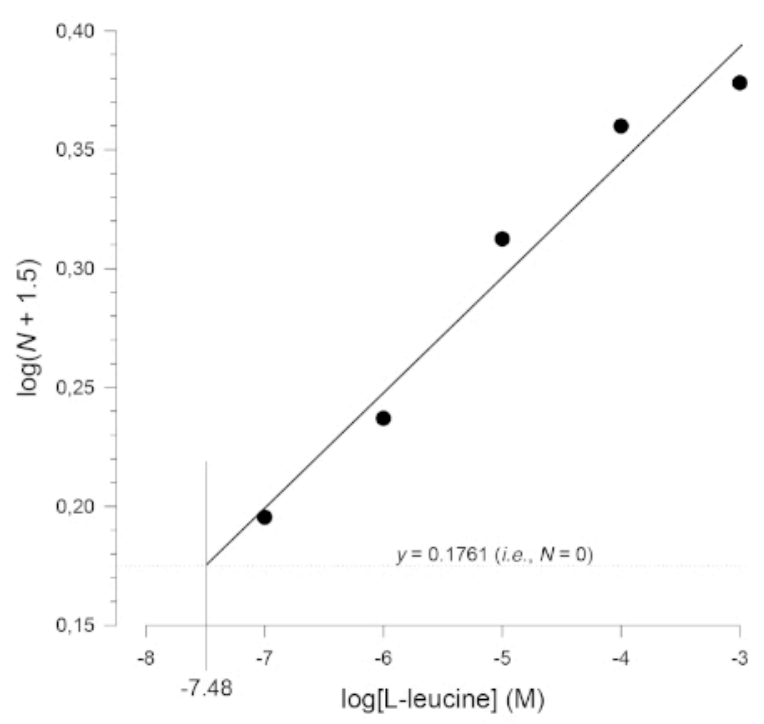

Figure 5: Typical concentration-response curve for L-leucine recorded extracellularly from the olfactory nerve in

vivo. (A) As the concentration of L-leucine applied to the olfactory epithelium (horizontal bars) increases from $10^{-7} \mathrm{M}$ to $10^{-3}$ $\mathrm{M}$, a concomitant increase in activity is seen in the nerve. Upper traces show the integrated responses and lower traces show the raw (nerve) signal. $(B)$ Linear regression $\left(R^{2}=0.97\right)$ of normalized data plotted semi-logarithmically to calculate threshold of detection as the value for $\log [$ L-leucine] when $\log (N+1.5)=0.1761$ (i.e., where $N=0$ ). In this example, this value is -7.48 ; the estimated threshold of detection for L-leucine in this fish is therefore $10^{-7.48} \mathrm{M}$. Please click here to view a larger version of this figure. 


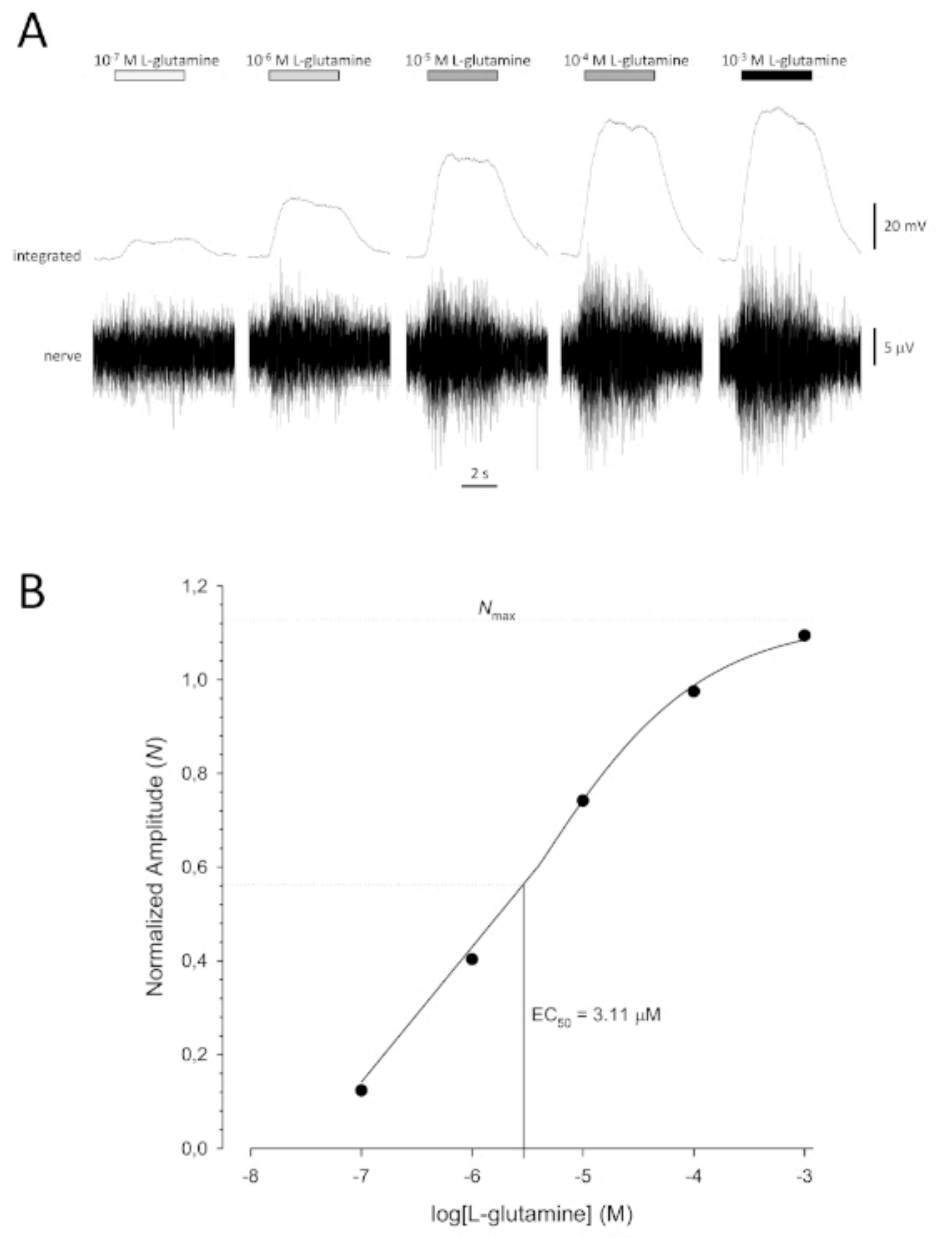

Figure 6: Typical concentration-response curve for L-glutamine recorded extracellularly from the olfactory nerve in vivo. (A) As the concentration of L-glutamine applied to the olfactory epithelium (horizontal bars) increases from $10^{-7} \mathrm{M}$ to $10^{-3} \mathrm{M}$, a concomitant increase in activity is seen in the nerve. Upper traces show the integrated responses and lower traces show the raw (nerve) signal. (B) Semi-logarithmic plot of normalized data fitted to a three-parameter Hill equation $\left(R^{2}\right.$ $=0.99)$. For this example, the calculated $\mathrm{EC}_{50}=3.11 \mu \mathrm{M}$, and the Hill co-efficient $\left.=0.565\right)$. Please click here to view a larger version of this figure.

\section{Discussion}

The current study describes the use of multi-unit (extracellular) recording from the olfactory nerve of the seabream ( $S$. aurata), a marine sparid of great importance in aquaculture. However, this experimental approach can be broadly applied to other fish; the surgery and exact placement of electrodes will clearly depend on the anatomy of the olfactory system, and the choice and concentration of anesthetic may depend on the species under study. For example, the olfactory nerve of the goldfish (Carassius auratus) is short; in this case, recording the EEG from 
the olfactory bulb would be easier. The choice of odorant may also depend, to some extent, on the species. The current study used amino acids. As far as the authors are aware, all fish species investigated to date have olfactory sensitivity to amino acids ${ }^{1,18}$. This sensitivity has been implicated is diverse processes such as food location, chemical communication and recognition of natal waters $^{19,20,21,22,23}$. However, the sensitivities of different species are, broadly speaking, rather similar and do not depend on lifestyle or habitat. They are also well-defined molecules and are cheaply and easily available. These reasons make them ideal test stimuli for studies on olfaction in fish, especially those investigating the effects of anthropogenic disturbances (e.g., acidification or pollution), where results can be easily compared across species ${ }^{24}$.

Depending on the species in question, preparations for multiunit recording can remain stable for several hours; the amplitude of response to the internal standard $\left(10^{-3} \mathrm{M} \mathrm{L-}\right.$ serine in the current study) should not vary by more than $10 \%$ between successive tests. Any significant deviation from this rule of thumb could be due to: (i) movement of the fish, and therefore displacement of the electrodes and/or nosetube; (ii) contamination of the water, for example, by coming into contact with the experimenter's hands (especially if lower concentrations of a given odorant give larger responses than higher concentrations); or (iii) deterioration of the health of the preparation). In case (i), the fish should be checked for having moved; if so, reposition it, and add more anesthetic to the water and/or give another dose of gallamine triethiodide. Allow $5 \mathrm{~min}$ and retest the standard. If the response is still smaller, then reposition the electrodes and/or nose-tube until a sufficiently large response is recorded. In case (ii), simply remake a fresh dilution series of the odorant, using clean glassware and water. In case (iii), check that the flow of water over the fish's gills is adequate, that the water is flowing over the gills (i.e., exiting via the opercula, rather than the mouth), and the water is well-aerated. Different fish species have widely different temperature preferences; ensure that the laboratory) temperature (and that of the water in contact with the fish) is as close to the temperature that the fish are kept at as possible. Ensure, too, that the fish are not stressed, and avoid moving them (even from one tank to another) for at least a week prior to recording. Electrical noise is, of course, the bane of an electrophysiologist's life; however, the current article is not the appropriate medium to discuss how to overcome/reduce this. Nevertheless, 'The Axon Guide' (available freely as a pdf for download from the manufacturer's website) is a source of practical advice on noise minimization. Once a large, stable response is evoked by the standard stimulus, and a concentration series gives a concentration-dependent increase in amplitude, with minimal response to the blank, recording responses to test stimuli can begin. Some authors give the same stimulus three times, and calculate the arithmetic mean for subsequent data analysis. However, these are technical replicates, and this approach will increase the time a recording session takes by three-fold. The current authors prefer to test a given odorant once, but always part of a concentration-response curve. This not only allows the calculation of the threshold of detection or EC 50 (as described), but also ensures that concentrations close to those that the fish would experience in its natural environment are tested (this is not always known). Furthermore, any outlier responses, due to contamination for example, are easier to spot; these can then be repeated using a freshly made sample if necessary.

Multi-unit recording from the olfactory nerve may be invasive, but it is more sensitive than the EOG when recorded in seawater ${ }^{7}$, as it is independent of external salinity. It 
can therefore be used to assess olfactory sensitivity to odorants, such as calcium and sodium, changes in the concentrations of which would also affect conductivity and consequently voltages recorded ${ }^{15}$. As an estimate of the number of ORNs responding to a given odor (i.e., action potentials travelling along ORN axons from the olfactory epithelium to the bulb), it represents a raw, unprocessed signal (initial processing of olfactory input begins in the bulbs). Therefore, it is a better parameter to assess the direct effects of pollutants, such as heavy metals, and environmental changes, such as $\mathrm{pH}$, on the olfactory system than the $E O G$ or $E E G^{24,25}$. Recording from the olfactory bulb in seawater with high $\mathrm{PCO}_{2}$ (and therefore low $\mathrm{pH}$ ) may be affected by central effects of $\mathrm{pH}$ on neural processing; the 'GABAA receptor theory' of ocean acidification ${ }^{26}$, whereby reduction in water $\mathrm{pH}$ causes a redistribution of $\mathrm{Cl}^{-}$and $\mathrm{HCO}_{3}{ }^{-}$ion in the CSF and a consequent shift of GABAergic activation from inhibitory (hyperpolarizing) to excitatory (depolarizing). Furthermore, in such studies, it is important to assess the effects of acidification or pollutants using odorant concentrations similar to those the fish is likely to encounter in its natural environment. For amino acids, this is in the nano to micromolar range $27,28,29$; close to the threshold of detection of these compounds in fish ${ }^{1,18}$. Estimation of the threshold of detection for a given odorant can give some idea of the importance and/or biological role of the olfactory sensitivity. For example, the sea lamprey (Petromyzon marinus) has high olfactory sensitivity to specific bile acids released by larvae down to a threshold of $10^{-13}$ $\mathrm{M}^{30}$; this sensitivity allows adults to locate and identify suitable spawning grounds, and therefore act as a migratory pheromone over long distance. Similarly, ripe female sea lamprey have high olfactory sensitivity to spermine (threshold $\left.10^{-14} \mathrm{M}\right)$, a polyamine released in the milt by males, which then attracts them to the nests of spermiating males ${ }^{31}$. Other fish also have olfactory sensitivity to polyamines $32,33,34,35$, but not with sufficiently low thresholds of detection to support a similar pheromonal role; instead, avoidance of decaying fish is suggested. Nevertheless, with such high olfactory sensitivities, it is possible to imagine that a slight reduction in sensitivity (i.e., increase in threshold), even when the response amplitude is not dramatically reduced, could cause severe problems for fish ${ }^{24}$.

When plotted semi-logarithmically, concentration-response curves to odorants can be exponential, linear or sigmoidal $^{18}$. In the case of amino acids, such semilogarithmic concentration-response curves are either linear (i.e., logarithmic), sigmoidal or power functions ${ }^{7}$. That no saturation of the response is seen (i.e., no plateau in the concentration-response curve, even at supra-environmental concentrations) is probably due to several receptors binding to individual amino acids, depending on their concentration, rather than each amino acid binding to a specific receptor; as the concentration of a given amino acid increases, more receptors are able to bind it and therefore respond. Nevertheless, fish can distinguish between mixtures of amino acids $^{36,37,38,39}$; this is likely due to combinatorial patterns of activity evoked in the olfactory bulbs ${ }^{12,40}$; the axons of all ORNs expressing the same receptor protein terminate at the same glomeruli in the olfactory bulbs ${ }^{41,42}$, and one amino acid can activate more than one glomerulus.

However, highly specific odorants, such as pheromones, may evoke sigmoidal or quasi-sigmoidal concentration-response curves $^{43,44}$. The inference, although not empirically tested, is that these olfactory responses are due to highly specific receptors which bind the pheromone molecule and little else. Therefore, above a given concentration, all receptors are occupied, and further increases will evoke no further 
responses in other ORNs. Therefore, these data can be fitted to a three-parameter Hill plot, and the maximal response, EC $_{50}$ and Hill co-efficient can be calculated ${ }^{15,45,46}$. This can give valuable information, such as apparent affinity and apparent receptor number, that linear or exponential concentration-response curves cannot give.

\section{Disclosures}

The authors have nothing to disclose.

\section{Acknowledgments}

Work in the authors' lab is supported by Fundação para a Ciência e a Tecnologia (FCT), Portugal, projects PTDC/BIABMA/30262/2017, ALG-01-0145-FEDER-030262 and UID/ Multi/04326/2019 and contract program DL57/2016/CP1361/ CT0041 to ZV.

\section{References}

1. Kasumyan, A. O. The olfactory system in fish: structure, function, and role in behaviour. Journal of Ichthyology. 44 (Suppl. 2), S180-S223 (2004).

2. Michel, W. C. Chemoreception. In The Physiology of Fishes. Edited by Evans, D. H., Claiborne, J. B. CRC Press, Boca Raton, FL. 471-497 (2006).

3. Wisenden, B. D. Chemical cues that indicate risk of predation. In Fish Pheromones and Related Cues. Edited by Sorensen, P. W., Wisenden, B. D. John Wiley \& Sons Inc., Ames, IA. 131-148 (2015).

4. Tierney, K. B. et al. Olfactory toxicity in fishes. Aquatic Toxicology. 96 (1), 2-26 (2010).

5. Caprio, J. In vivo olfactory and taste recordings in fish. In Experimental Cell Biology of Taste and Olfaction. Current Techniques and Protocols. Edited by Spielman,
A. I., Brand, J. G. CRC Press, Boca Raton, FL. 251-261 (1995).

6. Scott, J. W., Scott-Johnson, P. E. The electoolfactogram: a review of its history and uses. Microscopy Research and Technique. 58, 152-160 (2002).

7. Hubbard, P. C., Barata, E. N., Ozório, R. O. A., Valente, L. M. P., Canário, A. V. M. Olfactory sensitivity to amino acids in the blackspot seabream (Pagellus bogaraveo): a comparison between olfactory receptor recording techniques in seawater. Journal of Comparative Physiology A. 197 (8), 839-849 (2011).

8. Hamdani, E. H., Døving, K. B. The functional organization of the fish olfactory system. Progress in Neurobiology. $\mathbf{8 2}$ (2), 80-86 (2007).

9. Hara, T. J., Zhang, C. Topographic bulbar projections and dual neural pathways of the primary olfactory neurons in salmonid fishes. Neuroscience. 82 (1), 301-313 (1998).

10. Thommesen, G. The spatial distribution of odour induced potentials in the olfactory bulb of the char and trout (Salmonidae). Acta Physiologica Scandinavica. 102, 205-217 (1978).

11. Nikonov, A. A., Caprio, J. Electrophysiological evidence for a chemotopy of biologically relevant odors in the olfactory bulb of the channel catfish. Journal of Neurophysiology. 86 (4), 1869-1876 (2001).

12. Friedrich, R. W., Korsching, S. I. Chemotopic, combinatorial, and noncombinatorial odorant representations in the olfactory bulb revealed using a voltage-sensitive axon tracer. Journal of Neuroscience. 18 (23), 9977-9988 (1998). 
13. Pierrot, D. E., Lewis, E., Wallace, D. W. R. MS Excel programme developed for $\mathrm{CO}_{2}$ system calculations. ORNL/CDIAC-105a, Carbon Dioxide Information Analysis Center. Oak Ridge National Laboratory, US Department of Energy, Oak Ridge, TN. (2006).

14. Hubbard, P. C., Barata, E. N., Canário, A. V. M. Olfactory sensitivity to catecholamines and their metabolites in the goldfish. Chemical Senses. 28 (3), 207-218 (2003).

15. Hubbard, P. C., Barata, E. N., Canário, A. V. M. Olfactory sensitivity to changes in environmental $\left[\mathrm{Ca}^{2+}\right]$ in the marine teleost Sparus aurata. Journal of Experimental Biology. 203 (24), 3821-3829 (2000).

16. Hubbard, P. C., Ingleton, P. M., Bendell, L. A., Barata, E. N., Canário, A. V. M. Olfactory sensitivity to changes in environmental $\left[\mathrm{Ca}^{2+}\right]$ in the freshwater teleost Carassius auratus: an olfactory role for the $\mathrm{Ca}^{2+}$-sensing receptor? Journal of Experimental Biology. 205, 2755-2764 (2002).

17. Byrd, R. P., Jr, Caprio, J. Comparison of olfactory receptor (EOG) and bulbar (EEG) responses to amino acids in the catfish, Ictalurus punctatus. Brain Research. 249 (1), 73-80 (1982).

18. Hara, T. J. The diversity of chemical stimulation in fish olfaction and gustation. Reviews in Fish Biology and Fisheries. 4 (1), 1-35 (1994).

19. Kawabata, K. Induction of sexual behavior in male fish (Rhodeus ocellatus ocellatus) by amino acids. Amino Acids. 5 (3), 323-327 (1993).

20. Shoji, T., Yamamoto, Y., Nishikawa, D., Kurihara, K., Ueda, H. Amino acids in stream water are essential for salmon homing migration. Fish Physiology and Biochemistry. 28 (1-4), 249-251 (2003).
21. Yamamoto, Y., Hino, H., Ueda, H. Olfactory imprinting of amino acids in lacustrine sockeye salmon. PLOS ONE. 5 (1), e8633 (2010).

22. Kutsyna, O., Velez, Z., Canário, A. V. M., Keller-Costa, T., Hubbard, P. C. Variation in urinary amino acids in the Mozambique tilapia: a signal of dominance or individuality? In Chemical Signals in Vertebrates 13. Edited by Schulte, B., Goodwin, T., Ferkin, M. Springer, Cham, Switzerland. 189-204 (2016).

23. Velez, Z., Hubbard, P. C., Hardege, J. D., Barata, E. N., Canário, A. V. M. The contribution of amino acids to the odour of a prey species in the Senegalese sole (Solea senegalensis). Aquaculture. 265, 336-342 (2007).

24. Porteus, C. S. et al. Near-future $\mathrm{CO}_{2}$ levels impair the olfactory system of a marine fish. Nature Climate Change. 8 (8), 737-743 (2018).

25. Velez, Z., Roggatz, C. C., Benoit, D. M., Hardege, J. D., Hubbard, P. C. Short- and medium-term exposure to ocean acidification reduces olfactory sensitivity in gilthead seabream. Frontiers in Physiology. 10, 731 (2019).

26. Nilsson, G. E. et al. Near-future carbon dioxide levels alter fish behaviour by interfering with neurotransmitter function. Nature Climate Change. 2 (3), 201-204 (2012).

27. Fuhrman, J. A., Ferguson, R. L. Nanomolar concentrations and rapid turnover of dissolved free amino acids in seawater: agreement between chemical and microbiological measurements. Marine Ecology Progress Series. 33 (3), 237-242 (1986).

28. Pomeroy, L. R., Macko, S. A., Ostrom, P. H., Dunphy, J. The microbial food web in Arctic seawater: concentration of dissolved free amino acids and bacterial abaundance 
and activity in the Arctic Ocean and in Resolute Passage. Marine Ecology - Progress Series. 61 (1-2), 31-40 (1990).

29. Poulet, S. A., Williams, R., Conway, D. V. P., Videau, C. Co-occurrence of copepods and dissolved free amino acids in shelf sea waters. Marine Biology. 108 (3), 373-385 (1991).

30. Sorensen, P. W. et al. Mixture of new sulfated steroids functions as a migratory pheromone in the sea lamprey. Nature Chemical Biology. 1 (6), 324-328 (2005).

31. Scott, A. M. et al. Spermine in semen of male sea lamprey acts as a sex pheromone. PLoS Biology. 17 (7), e3000332 (2019).

32. Da Silva, J. P. et al. Synthetic versus natural receptors: supramolecular control of chemical sensing in fish. ACS Chemical Biology. 9 (7), 1432-1436 (2014).

33. Hussain, A. et al. High-affinity olfactory receptor for the death-associated odor cadaverine. Procedings of the National Academy of Sciences of the United States of America. 110 (48), 19579-19584 (2013).

34. Michel, W. C., Sanderson, M. J., Olson, J. K., Lipschitz, D. L. Evidence of a novel transduction pathway mediating detection of polyamines by the zebrafish olfactory system. Journal of Experimental Biology. 206 (10), 1697-1706 (2003).

35. Rolen, S. H., Sorensen, P. W., Mattson, D., Caprio, J. Polyamines as olfactory stimuli in the goldfish Carassius auratus. Journal of Experimental Biology. 206 (10), 1683-1696 (2003).

36. Kang, J., Caprio, J. Electro-olfactogram and multiunit olfactory receptor responses to complex mixtures of amino acids in the channel catfish, Ictalurus punctatus. Journal of General Physiology. 98 (4), 699-721 (1991).

37. Kang, J., Caprio, J. Electrophysiological responses of single olfactory bulb neurons to binary mixtures of amino acids in the channel catfish, Ictalurus punctatus. Journal of Neurophysiology. 74 (4), 1435-1443 (1995).

38. Valentincic, T., Kralj, J., Stenovec, M., Koce, A., Caprio, J. The behavioral detection of binary mixtures of amino acids and their individual components by catfish. Journal of Experimental Biology. 203, 3307-3317 (2000).

39. Valentincic, T., Wegert, S., Caprio, J. Learned olfactory discrimination versus innate taste responses to amino acids in channel catfish (Ictalurus punctatus). Physiology and Behavior. 55 (5), 865-873 (1994).

40. Friedrich, R. W., Korsching, S. I. Combinatorial and chemotopic odorant coding in the zebrafish olfactory bulb visualized by optical imaging. Neuron. 18 (5), 737-752 (1997).

41. Vassar, R. et al. Topographic organization of sensory projections to the olfactory bulb. Cell. 79 (6), 981-991 (1994).

42. Mombaerts, P. et al. Visualizing an olfactory sensory map. Cell. 87 (4), 675-686 (1996).

43. Keller-Costa, T. et al. Identity of a tilapia pheromone released by dominant males that primes females for reproduction. Current Biology. 24 (18), 2130-2135 (2014).

44. Sorensen, P. W., Hara, T. J., Stacey, N. E. Extreme olfactory sensitivity of mature and gonadally-regressed goldfish to a potent steroidal pheromone, 17a,20bdihydroxy-4-pregnen-3-one. Journal of Comparative Physiology A. 160 (3), 305-313 (1987). 
45. Keller-Costa, T., Canário, A. V. M., Hubbard, P. C. Olfactory sensitivity to steroid glucuronates in Mozambique tilapia suggests two distinct and specific receptors for pheromone detection. Journal of Experimental Biology. 217 (23), 4203-4212 (2014).

46. Hubbard, P. C., Mota, V., Keller-Costa, T., da Silva, J. P., Canário, A. V. M. Chemical communication in tilapia: a comparison of Oreochromis mossambicus with O. niloticus. General and Comparative Endocrinology. 207, 13-20 (2014). 